\title{
Design of a Compact Quad-Band Slot Antenna for Integrated Mobile Devices
}

\author{
Jian Dong, Xiaping Yu, and Guoqiang Hu \\ School of Information Science and Engineering, Central South University, Changsha 410083, China \\ Correspondence should be addressed to Jian Dong; dongjian@csu.edu.cn
}

Received 9 February 2016; Revised 2 June 2016; Accepted 9 June 2016

Academic Editor: Wenhua Yu

Copyright ( 2016 Jian Dong et al. This is an open access article distributed under the Creative Commons Attribution License, which permits unrestricted use, distribution, and reproduction in any medium, provided the original work is properly cited.

\begin{abstract}
In order to incorporate different communication standards into a single device, a compact quad-band slot antenna is proposed in this paper. The proposed antenna is composed of a dielectric substrate, T-shaped microstrip patch with a circle slot and an inverted L-slot, and a comb-shaped ground on the back of the substrate. By adopting these structures, it can produce four different bands, while maintaining a small size and a simple structure. Furthermore, a prototype of the quad-band antenna is designed and fabricated. The simulated and measured results show that the proposed antenna can operate over the $1.79-2.63 \mathrm{GHz}, 3.46-3.97 \mathrm{GHz}$, 4.92-5.85 GHz, and 7.87-8.40 GHz, which can cover entire PCS (Personal Communications Service, 1.85-1.99 GHz), UMTS (Universal Mobile Telecommunications System, 1.92-2.17 GHz), WCDMA (wideband code-division multiple access, 2.1 GHz), Bluetooth (2.4-2.48 GHz), WiBro (Wireless Broad band access service, 2.3-3.39 GHz), WLAN (Wireless Local Area Networks, 2.4/5.2/5.8 GHz), WiMAX (Worldwide Interoperability for Microwave Access, 2.5/3.5/5.5 GHz), and X-band SATcom applications $(7.9 \sim 8.4 \mathrm{GHz})$. The proposed antenna is particularly attractive for mobile devices integrating multiple communication systems.
\end{abstract}

\section{Introduction}

Modern wireless communication devices are often required to integrate multiple standards and services, operating at different frequency bands, into a single portable handset [1] Thus, it is highly desirable to design multiband antennas to meet the needs of multiple communication standards. For PCS, UMTS, and WCDMA operations, the ideal frequency bands are $1.9 \mathrm{GHz}$ and $2.1 \mathrm{GHz}$ in a single antenna. As for WLAN/WiMAX applications, the operating bands assigned by IEEE 802.11 are $2.4 \mathrm{GHz}(2.4-2.484 \mathrm{GHz}), 5.2 / 5.8 \mathrm{GHz}$ (5.15-5.35 GHz/5.725-5.825 GHz), and $2.5 / 3.5 / 5.5 \mathrm{GHz}(2.5-$ 2.69/3.4-3.69/5.25-5.85 GHz). Many antennas have been recently reported in the literature to cover such applications, but most of them are single-band or dual-band [2-4]. Obviously, few bands limit their applications. Thus, some designs were proposed to operate covering triband applications $[5,6]$. In [5], a symmetrical L-slot antenna was designed covering $2.34-2.82 \mathrm{GHz}, 3.16-4.06 \mathrm{GHz}$, and $4.69-5.37 \mathrm{GHz}$. A triband microstrip slot antenna for WLAN/WiMAX application was presented in [6]. The common problem is that these designs can only cover more than $2.3 \mathrm{GHz}$ frequency applications, but lower frequency band applications are not involved, such as PCS $(1.9 \mathrm{GHz})$ and WCDMA $(2.1 \mathrm{GHz})$. Furthermore, many antennas have large size and complex structure which are not suitable for space-constrained portable wireless terminals. In [7], an antenna with I-shaped monopole was printed in the area of $28 \mathrm{~mm} \times 29 \mathrm{~mm}$. A multiband antenna with $\mathrm{H}$-shaped slot was presented in [8] with the area of $60 \mathrm{~mm} \times 60 \mathrm{~mm}$. A multiband internal antenna for all commercial mobile communication bands and $802.11 \mathrm{a} / \mathrm{b} / \mathrm{g} / \mathrm{n}$ WLAN was designed in [9] with the area of $40 \mathrm{~mm} \times 20 \mathrm{~mm}$. In [10], a small CPW- (coplanar-waveguide-) fed multiband antenna consisting of a square-spiral patch with two L-shape strips was reported. However, the coverage of WiMAX/WLAN applications in $[9,10]$ is not complete. In [11], a compact antenna with symmetrical L-strips was reported for WLAN/WiMAX operations; however, the three resonant frequencies cannot be adjusted independently. A CPW-fed monopole antenna was proposed in [12], which covers lots of applications but all are below $3 \mathrm{GHz}$ frequency.

In this paper, a compact quad-band antenna with a circle slot and an inverted L-slot on the radiating patch as well as a comb-shaped ground structure is proposed not only to obtain 
TABLE 1: Performance comparison of the proposed antenna with other reported antennas.

\begin{tabular}{|c|c|c|c|c|}
\hline Reference & Size & Operating bands (GHz) & Peak gain $(\mathrm{dBi})$ & Remarks \\
\hline [2] & $60 \times 12$ & $0.9-1.9$ & 5.2 & \multirow{2}{*}{$\begin{array}{l}\text { Few useful frequency bands or too large overall } \\
\text { size }\end{array}$} \\
\hline [3] & $40 \times 35$ & $2.26-2.42,3.29-3.6$ & 3.3 & \\
\hline$[4]$ & $40 \times 10$ & $2.38-2.52,3.40-3.62$ & 2.7 & Few useful frequency bands \\
\hline [5] & $23 \times 36.5$ & $\begin{array}{l}2.33-2.76,3.05-3.88 \\
5.57-5.88\end{array}$ & 3.0 & \multirow[t]{2}{*}{ Only $>2.3 \mathrm{GHz}$ applications } \\
\hline [6] & $38 \times 25$ & $2.4-2.7,3.1-4.15,4.93-5.89$ & 2.9 & \\
\hline [7] & $29 \times 28$ & $0.79-0.92,1.71-2.28$ & 3.25 & Few useful frequency bands \\
\hline [8] & $60 \times 60$ & $\begin{array}{l}1.55-1.57,2.395-2.695 \\
4.975-5.935\end{array}$ & 3.7 & Too large overall size \\
\hline [9] & $40 \times 20$ & $0.82-2.69,5.15-5.825$ & 3.5 & \multirow{2}{*}{$\begin{array}{l}\text { Incomplete coverage of WIMAX/WLAN } \\
\text { applications }\end{array}$} \\
\hline [10] & $20 \times 20$ & $\begin{array}{l}2.33-2.809,3.36-3.54 \\
5.811-5.987,7.994-8.486\end{array}$ & Not mentioned & \\
\hline [11] & $32 \times 28$ & $\begin{array}{l}2.34-2.82,3.16-4.06 \\
4.69-5.37\end{array}$ & 3.18 & Nonindependently tuned resonant frequencies \\
\hline [12] & $67 \times 38$ & $0.863-1.049,1.49-2.81$ & Not mentioned & Only $<3 \mathrm{GHz}$ applications \\
\hline Proposed antenna & $20 \times 30$ & $\begin{array}{l}1.79-2.63,3.49-3.97 \\
4.92-5.85,7.87-8.40\end{array}$ & 6.9 & Compact size and sufficient bands \\
\hline
\end{tabular}

good quad-band operational performance but also to achieve a smaller size and simpler structure with respect to the previous designs. By combining different resonant structures, the proposed antenna can generate four resonant modes to cater for the desired bands of PCS, WCDMA, UMTS, Bluetooth, WLAN, WiMAX, and X-band applications. It is evident from Table 1 that the proposed antenna has more a compact size and more sufficient frequency bands as compared to the other mentioned antennas. Details of antenna design and simulated and measured results will be carefully examined and discussed in the following sections.

\section{Antenna Design}

A schematic view of the proposed slot microstrip-fed planar antenna for quad-band application is shown in Figure 1. The antenna is printed on a $1.6 \mathrm{~mm}$ thick FR4 substrates with relative permittivity of 4.4 and loss tangent 0.02 , while the overall areas are only $20 \times 30 \mathrm{~mm}^{2}$. In order to miniaturize the size of the portable devices antenna, the radiator width is set to be the same as the width of the microstrip feed line. The proposed antenna consists of a $\mathrm{T}$-shaped radiating patch and a comb-shaped ground. There is a circular slot (Radius $R_{1}$ ) on the broad rectangle of the T-shaped patch and an inverted L-shaped slot of length $L_{c 1}$ and width $W_{c 1}$ on the narrow rectangle of the $\mathrm{T}$-shaped patch. The conventional rectangle ground is transformed into a comb-shaped ground structure by cutting rectangular slots to excite $2.4 / 5.5 \mathrm{GHz}$ applications. In order to achieve $50 \Omega$ characteristic impedance, the antenna is fed with a $2.8 \mathrm{~mm}$ wide microstrip line. The final antenna design is achieved by tuning the length, width, and the slot dimensions of the radiating patch and the combshaped ground structure. All the parameters are optimized with Ansoft HFSS and summarized in Table 2. Detailed

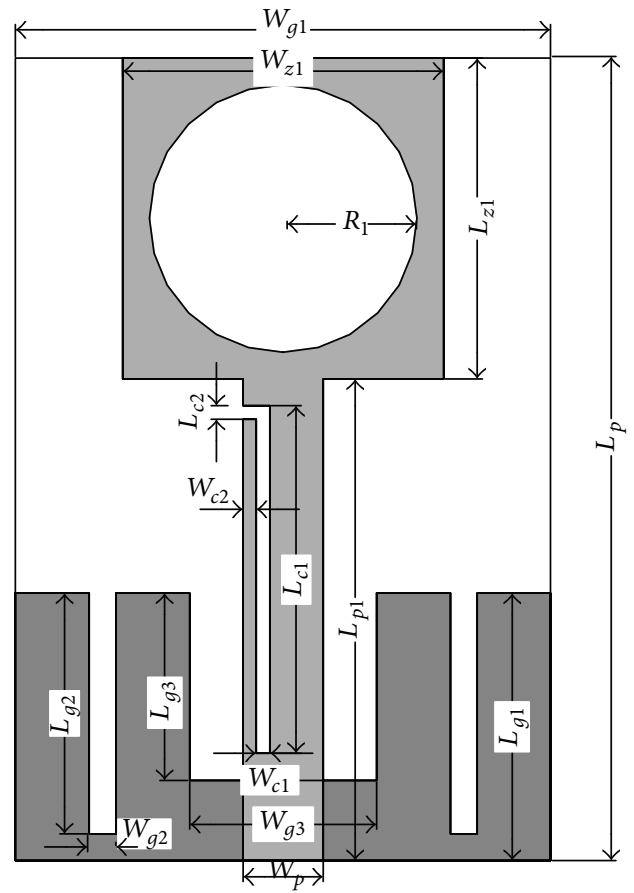

Figure 1: Geometry of the proposed quad-band slot antenna.

analysis of the proposed antenna will be given from the following three aspects.

2.1. Design Principle. Etching slots is one of the most efficient techniques in multiband antenna miniaturization. For a given shape and size of the radiating patch (or the ground plane), cutting slots on it will change the surface current distribution and increase the effective current path length (see 
TABLE 2: Parameters of the proposed antenna (unit: $\mathrm{mm}$ ).

\begin{tabular}{lcccccrr}
\hline$W_{g 1}$ & $L_{g 1}$ & $L_{p}$ & $L_{p 1}$ & $W_{p}$ & $W_{z 1}$ & $L_{z 1}$ & $L_{g 2}$ \\
\hline 20 & 12 & 30 & 18 & 2.8 & 12 & 9 \\
\hline$W_{g 2}$ & $L_{g 3}$ & $W_{g 3}$ & $L_{c 1}$ & $W_{c 1}$ & $L_{c 2}$ & $W_{c 2}$ & $R_{1}$ \\
\hline 1 & 7 & 7.3 & 13.4 & 0.5 & 0.5 & 4.8 \\
\hline
\end{tabular}

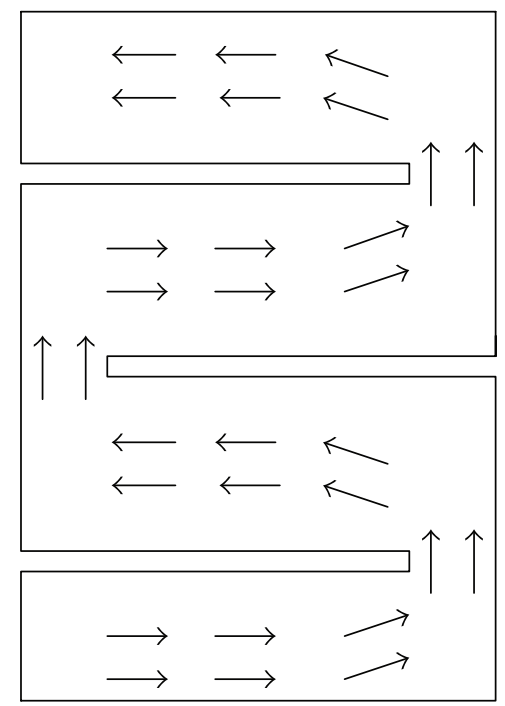

FIGURE 2: Schematic diagram of surface current distribution on rectangular patch with slots.

in Figure 2). Therefore, the resonant frequency will drop significantly. Similarly, for a given resonant frequency, the size of the antenna will be significantly reduced by cutting slots on the radiating patch or on the ground plane. Also, the bandwidth of the antenna will be broadened because of the decreased $Q$ value resulting from etching slots.

In our proposed antenna, the $\mathrm{T}$-shaped radiating patch and the rectangular ground act as wideband impedance matching. Note that the effective length of the slots, $L$, can be approximately calculated by [13]

$$
L=\frac{c}{4 f_{0} \sqrt{\varepsilon_{e}}}
$$

where $f_{0}$ is the resonance frequency, $c$ stands for the freespace velocity of light, $\varepsilon_{e}=\left(\varepsilon_{r}+1\right) / 2$ is the effective permittivity of the dielectric substrate, and $\varepsilon_{r}$ is the relative permittivity. Assuming that the antenna works at $3.5 \mathrm{GHz}$, the inverted $L$ slot length is about $13 \mathrm{~mm}$. Also, the lengths of the other slots can be estimated in the similar way.

2.2. Structural Analysis. Figure 3 shows the evolution of the proposed antenna and its corresponding simulated results of return loss. It begins from the design of Antenna (1), which consists of a $\mathrm{T}$-shaped radiation patch (having no slots) and a comb-shaped ground structure. This simple design can obtain two wide bands of $1.92-3.09 \mathrm{GHz}$ and $4.77-6.81 \mathrm{GHz}$ as shown in Figure 3(b), which cover the WLAN/WiMAX standard applications. In order to excite $3.5 \mathrm{GHz}$ resonant mode, an inverted L-slot on the narrow rectangle of the Tshaped radiation patch is introduced in Antenna (2). The corresponding $-10 \mathrm{~dB}$ return loss bandwidth is $580 \mathrm{MHz}$ (3.37-3.95 GHz) as shown in Figure 3(b). Finally, in order to generate the high frequency band, a circular slot is designed on the broad rectangle of the T-shaped patch in Antenna (3). The circular slot can independently yield a resonance operating at $8 \mathrm{GHz}$ band.

In order to further explain the quad-band operation property of the proposed antenna, the surface current distributions of the whole antenna at the frequencies of 2.5, 3.5, 5.5 , and $8 \mathrm{GHz}$ are given in Figure 4. It can be clearly seen from the figure that the current distributions are different in the four bands. In particular, when the antenna operates at $3.5 \mathrm{GHz}$, as shown in Figure $4(\mathrm{~b})$, most of the currents are concentrated near the inverted L-shaped slot. As shown in Figure 4(a), the rectangular slot in the middle of the comb-shaped ground with radiation patch produces $2.4 \mathrm{GHz}$ frequency band. As shown in Figure 4(c), the symmetrical rectangular slots on the comb-shaped ground with radiation patch produce $5.5 \mathrm{GHz}$ frequency band. When the antenna works at $8 \mathrm{GHz}$ frequency, as shown in Figure 4(d), currents are mainly distributed near the circular slot on the patch.

2.3. Parametric Study. To illustrate the effects of the critical parameters on the four different frequency bands (i.e., band I-2.4 GHz, band II-3.5 GHz, band III-5.5 GHz, and band IV$8 \mathrm{GHz}$ ), a parametric study on the quad-band antenna is carried out. From the parametric study, the optimum value for each parameter of the proposed antenna is obtained as listed in Table 2. Note that the presented antenna is sensitive to the geometrical parameters due to the miniaturized size. 


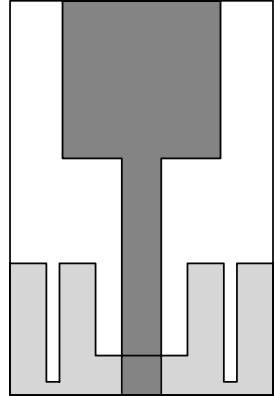

Antenna (1)

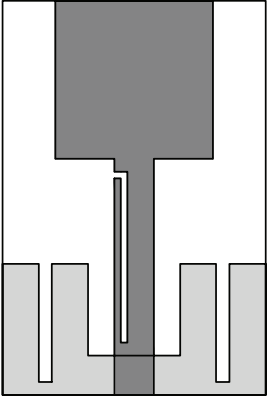

Antenna (2)

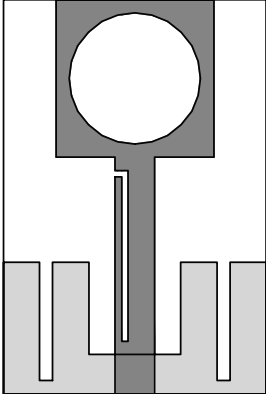

Antenna (3)

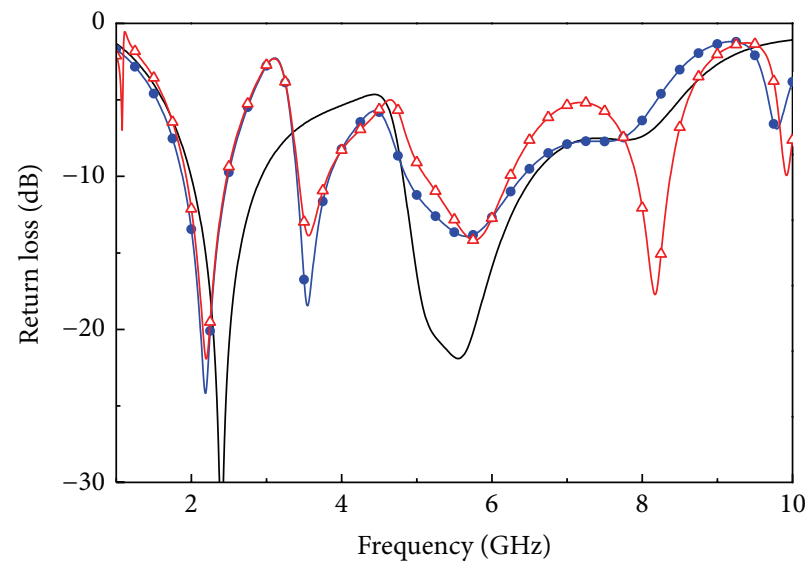

$\longrightarrow$ Antenna (1)
$\multimap$ Antenna (2)
$\triangle$ Antenna (3)

(a)

(b)

Figure 3: (a) Geometries of various antennas involved in the design evolution process. (b) Simulated return loss for the various antenna geometries.

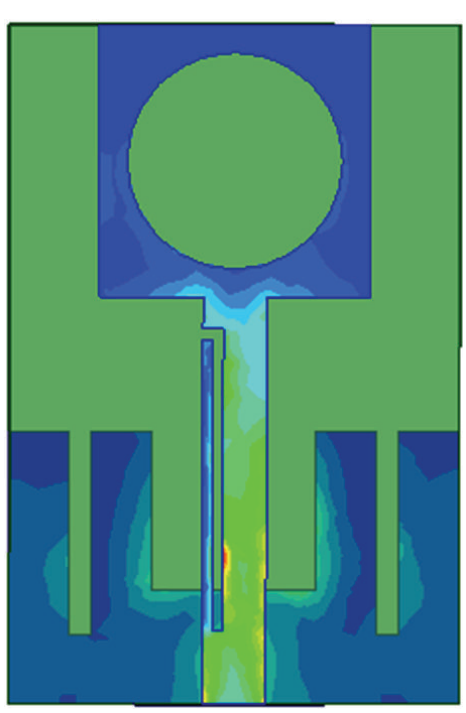

(a)

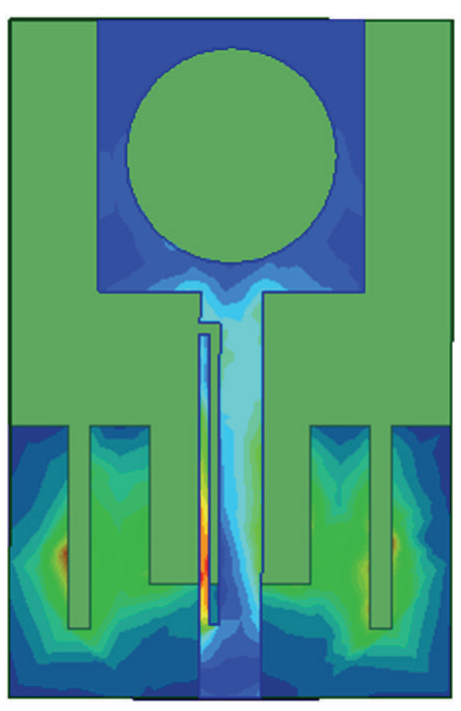

(c)

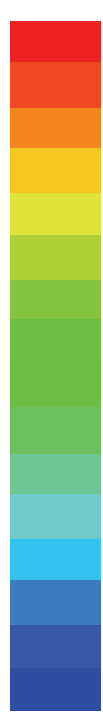

$8.8660 e+001$ $8.3122 e+001$ $7.7584 e+001$ $7.2046 e+001$ $6.6508 e+001$ $6.0970 e+001$ $5.5433 e+001$ $4.9895 e+001$ $4.4357 e+001$ $3.8819 e+001$ $3.3281 e+001$ $2.7744 e+001$ $2.2206 e+001$ $1.6668 e+001$ $1.1130 e+001$ $5.5922 e+000$ $5.4397 e-002$

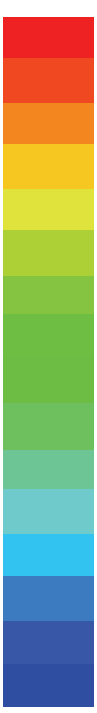

$1.4381 e+002$
$1.3483 e+002$
$1.2586 e+002$
$1.1688 e+002$
$1.0790 e+002$
$9.8928 e+001$
$8.9952 e+001$
$8.0976 e+001$
$7.2000 e+001$
$6.3024 e+001$
$5.4048 e+001$
$4.5072 e+001$
$3.6096 e+001$
$2.7121 e+001$
$1.8145 e+001$
$9.1686 e+000$
$1.9258 e-001$

$1.9258 e-001$
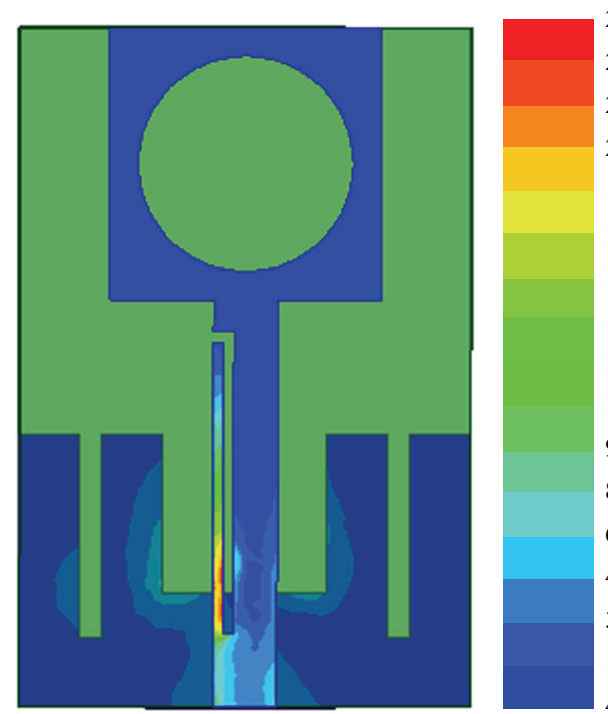

$2.6285 e+002$ $2.4645 e+002$ $2.3005 e+002$ $2.1365 e+002$ $1.9725 e+002$ $1.8085 e+002$ $1.6445 e+002$ $1.4805 e+002$ $1.3165 e+002$ $1.1525 e+002 \longleftarrow$ $9.8852 e+001$ 는 $8.2452 e+001$ $6.6051 e+001$ $4.9651 e+001$ $3.3251 e+001$ $1.6850 e+001$ $4.5021 e-001$

(b)
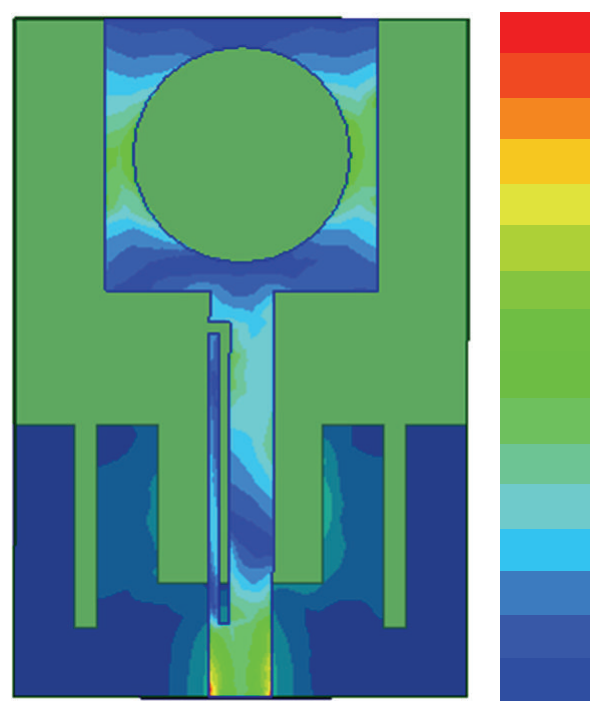

$1597 e+002$ $1.0873 e+002$ $1.0150 e+002$ $9.4264 e+001$ $8.7030 e+001$ $7.9796 e+001$ $7.2561 e+001$ $6.5327 e+001$ $5.8093 e+001$ $5.0859 e+001$ $4.3625 e+001-$ $3.6391 e+001$ $2.9157 e+001$ $2.1923 e+001$ $1.4689 e+001$ $7.4548 e+000$ $2.2073 e-001$

(d)

FIGURE 4: Surface current distributions of the proposed antenna at (a) 2.5, (b) 3.5, (c) 5.5, and (d) $8 \mathrm{GHz}$. 

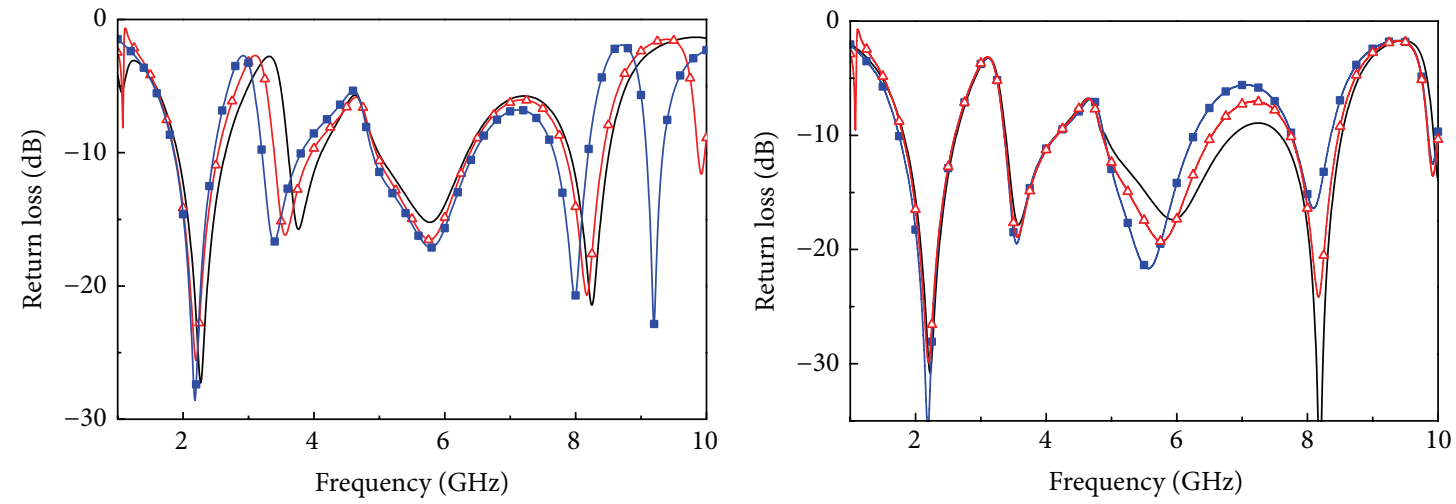

$$
\begin{aligned}
& \square L_{c 1}=14.4 \mathrm{~mm} \\
& \triangle L_{c 1}=13.4 \mathrm{~mm} \\
& -L_{c 1}=12.4 \mathrm{~mm}
\end{aligned}
$$

(a)

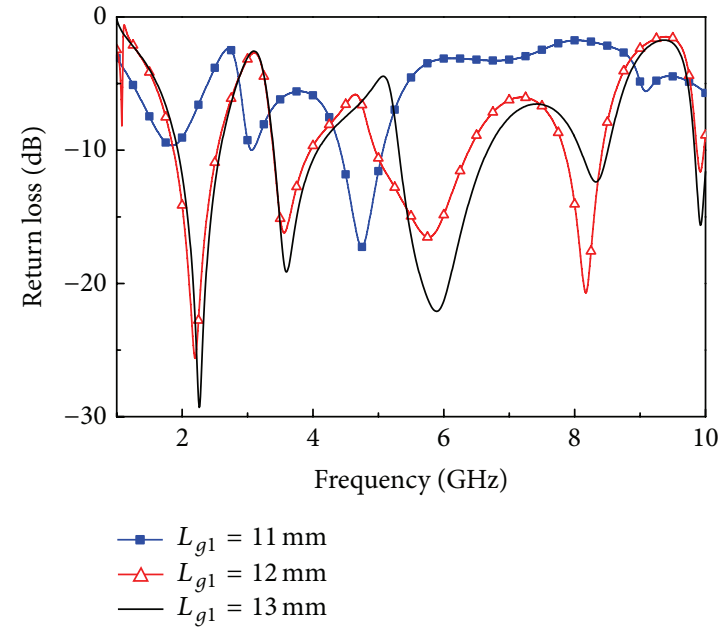

$$
\begin{aligned}
& \rightarrow R_{1}=4.4 \mathrm{~mm} \\
& \triangle R_{1}=4.8 \mathrm{~mm} \\
& -R_{1}=5.2 \mathrm{~mm}
\end{aligned}
$$

(b)

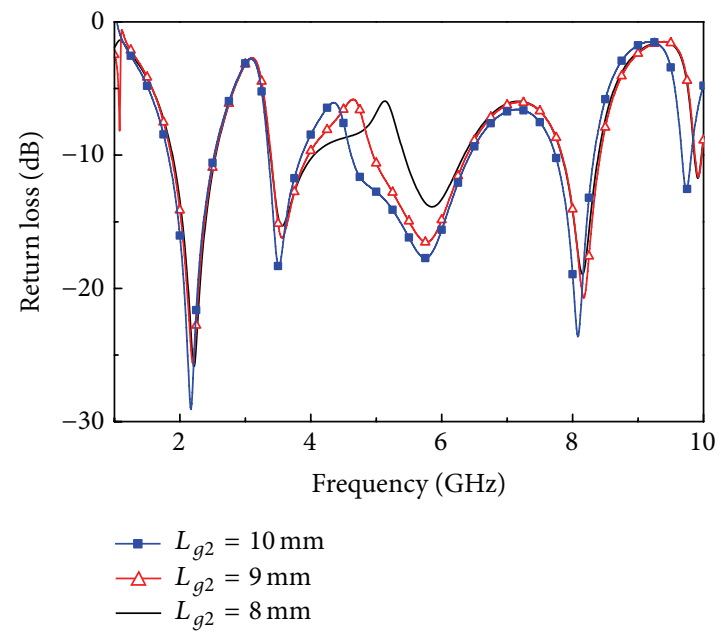

(c)

(d)

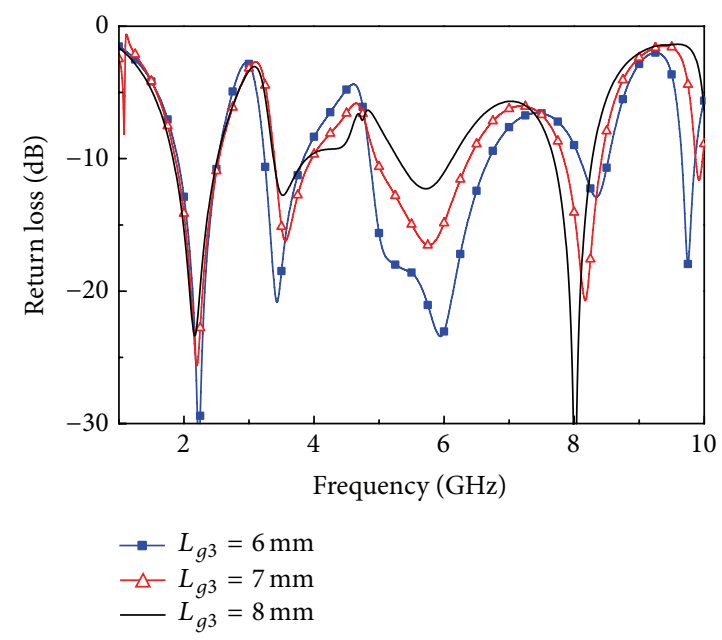

(e)

FIGURE 5: Simulated return loss of the antenna (a) as a function of $L_{c 1}$, the length of the inverted L-slot, (b) as a function of $R_{1}$, the radius of the circle slot, (c) as a function of $L_{g 1}$, the height of the comb-shaped ground, (d) as a function of $L_{g 2}$, the length of the symmetrical rectangular slots on the ground, and (e) as a function of $L_{g 3}$, the length of the middle rectangular slot on the ground; other parameters are the same as given in Table 2. 


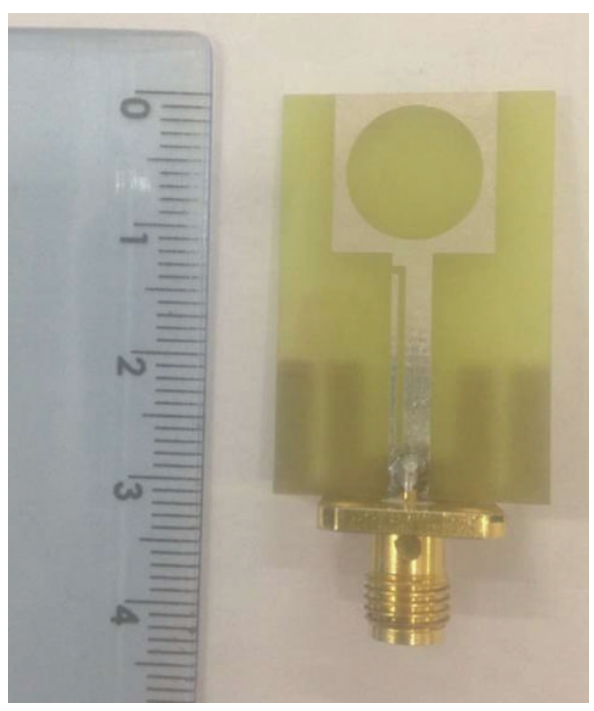

(a)

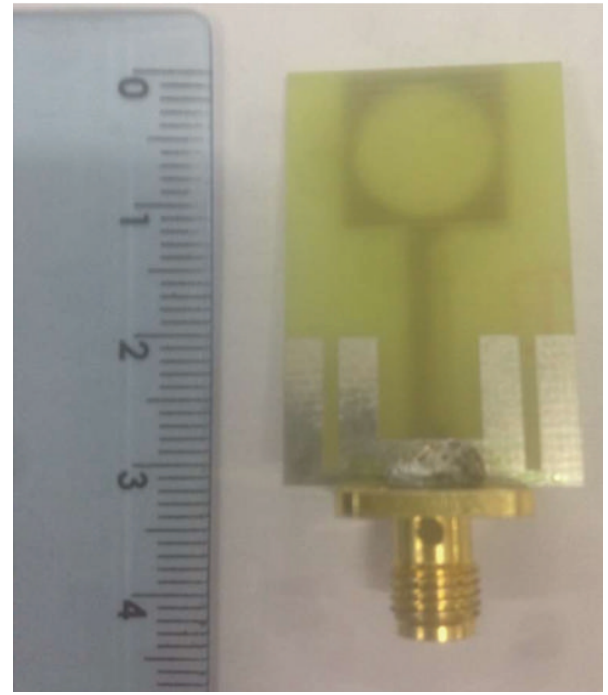

(b)

Figure 6: Fabricated prototype. (a) Top view. (b) Bottom view.

The dimensions of patch or ground slot are critical parameters in determining the sensitivity of impedance matching.

2.3.1. Variation of Patch Parameters. Keeping all the other parameters invariant, the effect of $L_{c 1}$ and the length of the inverted L-slot, on the return loss is depicted in Figure 5(a). It is observed from Figure 5(a) that the frequency bands shift toward lower frequency as $L_{c 1}$ is increased from $12.4 \mathrm{~mm}$ to $14.4 \mathrm{~mm}$. All the three curves cover bands I and III applications, but the curve of $12.4 \mathrm{~mm}$ cannot cover band II completely and the result of $14.4 \mathrm{~mm}$ cannot cover band IV completely. Thus, the value of $L_{c 1}$ is chosen $13.4 \mathrm{~mm}$ as an optimum. The effect of the radius of the circle slot, $R_{1}$, on the return loss is depicted in Figure 5(b). It can be observed from simulation results that as the values of $R_{1}$ increase from $4.4 \mathrm{~mm}$ to $5.2 \mathrm{~mm}$, the frequency bands shift toward higher frequency. It is also found that $R_{1}$ mainly affects bands III and IV while bands I and II almost remain unchanged. Combining the coverage of bands III and IV, the value of $R_{1}=4.8 \mathrm{~mm}$ is chosen as an optimum.

2.3.2. Variation of Ground Parameters. The height of the comb-shaped ground, $L_{g 1}$, on the return loss is depicted in Figure 5(c). It is shown when the value of $L_{g 1}$ is reduced to $11 \mathrm{~mm}$, the return loss has obvious degradation and only one resonant band is formed. Furthermore, at the value equal to $13 \mathrm{~mm}$, the antenna cannot cover bands III and IV completely. Thus, the optimum value for $L_{g 1}$ is chosen as $12 \mathrm{~mm}$.

The effect of the length of the symmetrical rectangular slots on the ground, $L_{g 2}$, on the return loss is depicted in Figure 5(d). It is shown from Figure 5(d) that as $L_{g 2}$ is increased from $8 \mathrm{~mm}$ to $10 \mathrm{~mm}$, the impedance bandwidth of band III is increased while other bands almost remain unchanged. Similar conclusion can be drawn from Figure 5(e) as the length of the middle rectangular slot on the ground, $L_{g 3}$, is reduced from $8 \mathrm{~mm}$ to $6 \mathrm{~mm}$. It is also found that $L_{g 3}$ slightly affects bands II and IV, but this effect can be adjusted back using other aforesaid parameters.

\section{Experimental Results and Discussion}

Based on the optimal dimensions listed in Table 2, a prototype of the quad-band antenna is fabricated and experimentally investigated. Figure 6 shows a photograph of the fabricated antenna. The simulated and measured results for the return loss of the proposed antenna are shown in Figure 7 . The simulated $-10 \mathrm{~dB}$ bandwidths range from 1.87 to $2.53 \mathrm{GHz}$, from 3.39 to $3.96 \mathrm{GHz}$, from 4.95 to $6.38 \mathrm{GHz}$, and from 7.84 to $8.42 \mathrm{GHz}$, and the measured bandwidths range from 1.79 to $2.63 \mathrm{GHz}$, from 3.46 to $3.97 \mathrm{GHz}$, from 4.92 to $5.85 \mathrm{GHz}$, and from 7.87 to $8.40 \mathrm{GHz}$. The discrepancy between the simulated and measured results could be mainly due to errors in processing and effect of the SMA connector. It can be concluded from return loss results that the proposed design has a good quad-band property which evidently covers entire PCS, WCDMA, WLAN, WiMAX, and X-band SATcom applications.

The gain values of the antenna with the frequency are shown in Figure 8 . The average gains through all the four bands vary from $2.5 \mathrm{~dB}$ to $6.9 \mathrm{~dB}$, showing that the antenna can provide stable gains in the four working frequency bands. The efficiency variations within different frequency bands are shown in Figure 9. It is observed from Figure 9 that the radiation efficiency of the antenna varies from $54 \%$ to $86.3 \%$.

Figure 10 shows the simulated and measured far-field radiation patterns in $x o z$ plane (E-plane) and xoy plane $(\mathrm{H}-$ plane) for frequencies at $2.5,3.5,5.5$, and $8 \mathrm{GHz}$, respectively. 


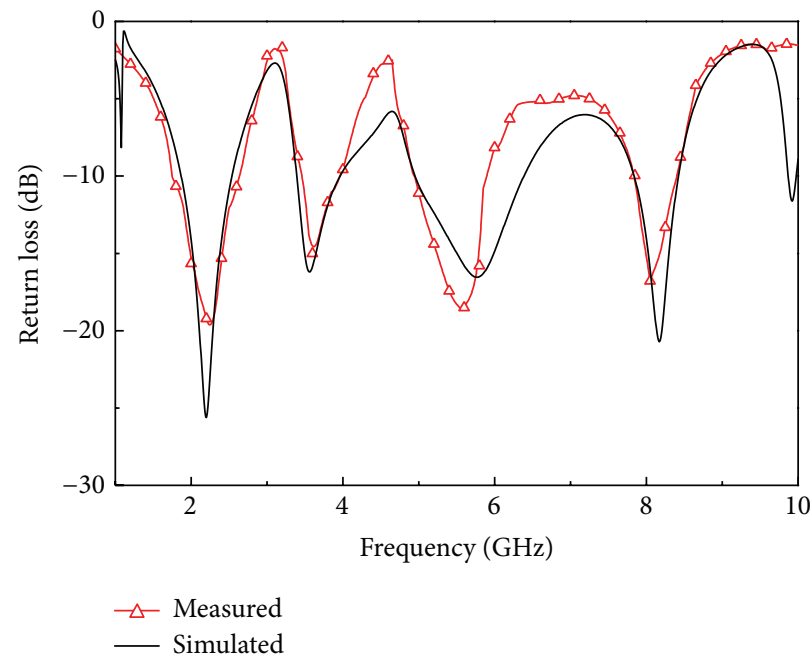

FiguRE 7: Simulated and measured results of the return loss of the proposed quad-band antenna.

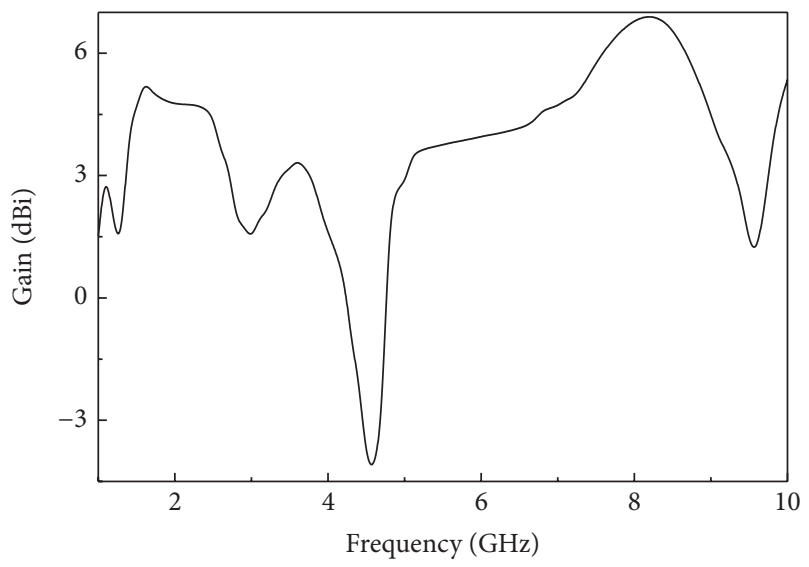

Figure 8: Gains of the proposed compact quad-band antenna.

From the figure, we can conclude that the proposed antenna features fairly good omnidirectional $\mathrm{H}$-plane patterns and bidirectional E-plane patterns over the desired operating bands. Radiation characteristics have obvious advantages over other similar multiband antennas; for example, in $[8,14]$, there are some sidelobes (especially at relatively high frequency band) in the radiation patterns which degrade the antenna radiation performance. The above radiation characteristics show that the proposed antenna is much preferable for the quad-band applications in the terminal design of integrated wireless communication systems.

\section{Conclusion}

A compact quad-band antenna with a circle slot and an inverted L-slot on the T-shaped radiating patch as well as a comb-shaped ground structure is proposed in this paper for incorporating different communication standards in a single device. The measured return loss indicates that the proposed antenna can operate over the bands of $1.79-2.63 \mathrm{GHz}, 3.46-$ $3.97 \mathrm{GHz}, 4.92-5.85 \mathrm{GHz}$, and $7.87-8.40 \mathrm{GHz}$, which comply

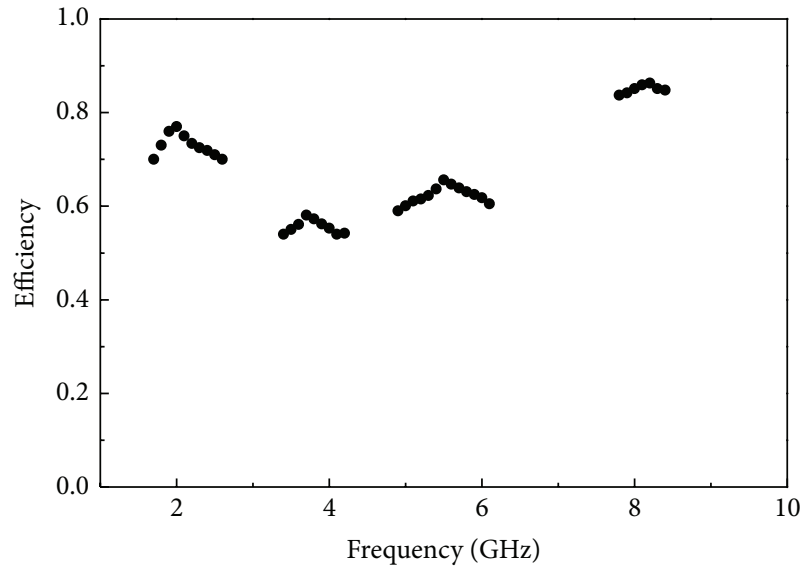

FIGURE 9: Efficiency variations within different frequency bands.

with the frequency needs of PCS, UMTS, WCDMA, Bluetooth, WLAN, WiMAX, and X-band uplink SATcom applications. The antenna exhibits a low profile, a compact size with simple structure, and largely omnidirectional radiation patterns. Since the antenna can be easily integrated with the circuit board and the handset enclosure, it is particularly attractive for portable devices incorporating multiple communication systems.

\section{Competing Interests}

The authors declare that there are no competing interests regarding the publication of this paper.

\section{Acknowledgments}

This work was supported in part by the National Science Foundation of China under Grant no. 61201086, in part by the China Scholarship Council under Grant no. 201506375060, in part by the Planned Science and Technology Project of 

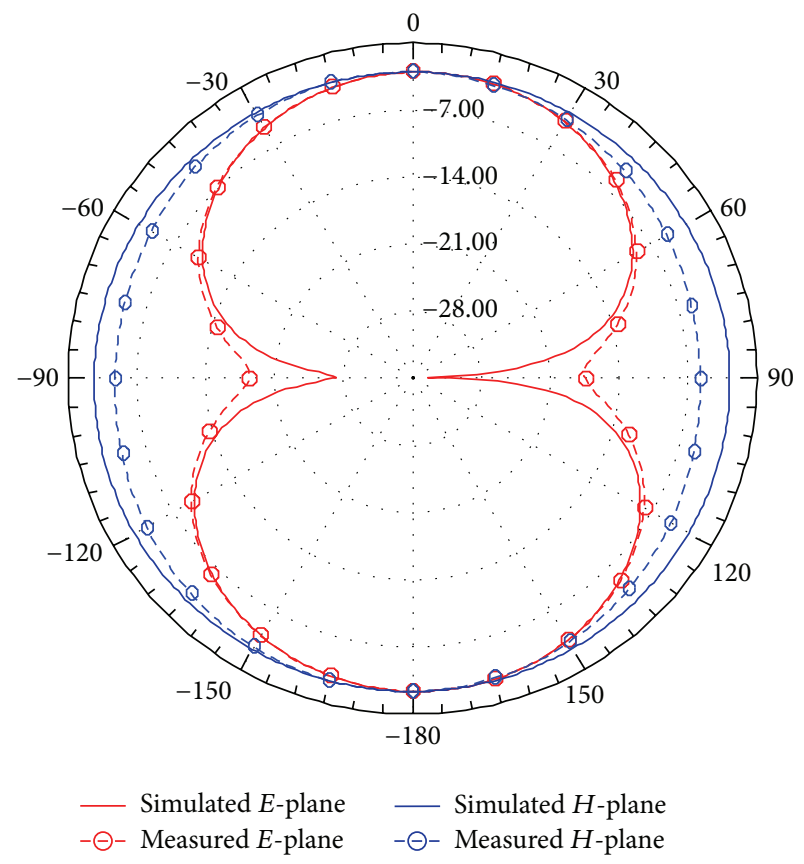

(a)

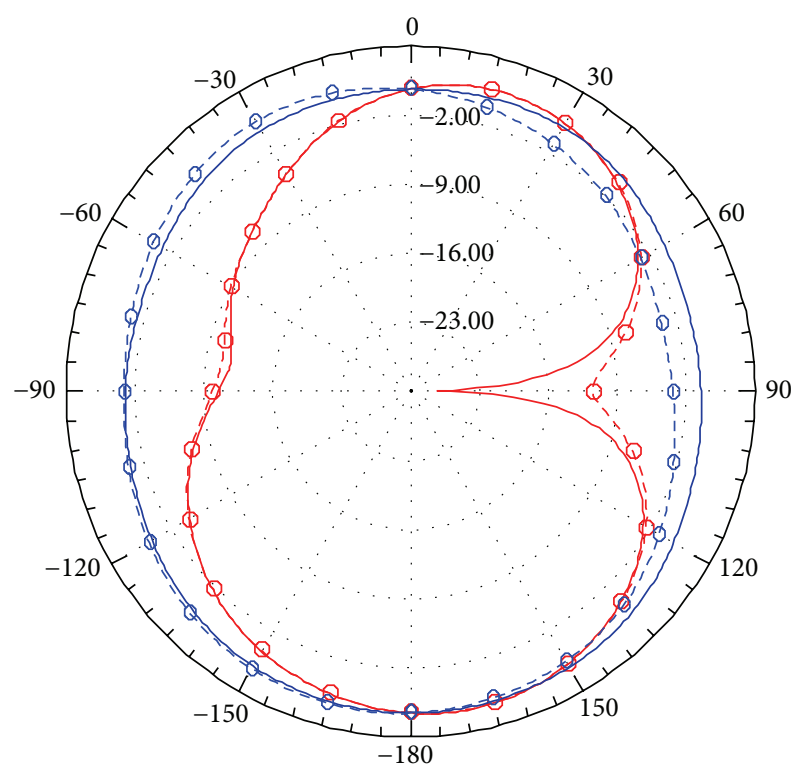

$\begin{array}{ll}\text { - Simulated } E \text {-plane } & - \text { Simulated } H \text {-plane } \\ -\Theta-\text { Measured } E \text {-plane } & -\Theta-\text { Measured } H \text {-plane }\end{array}$

(c)
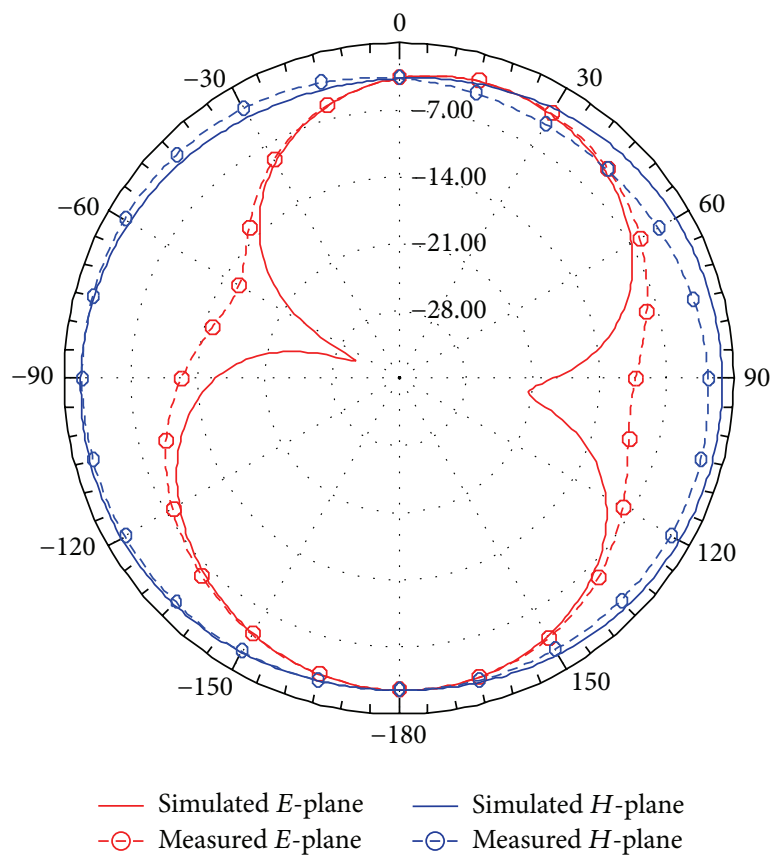

(b)
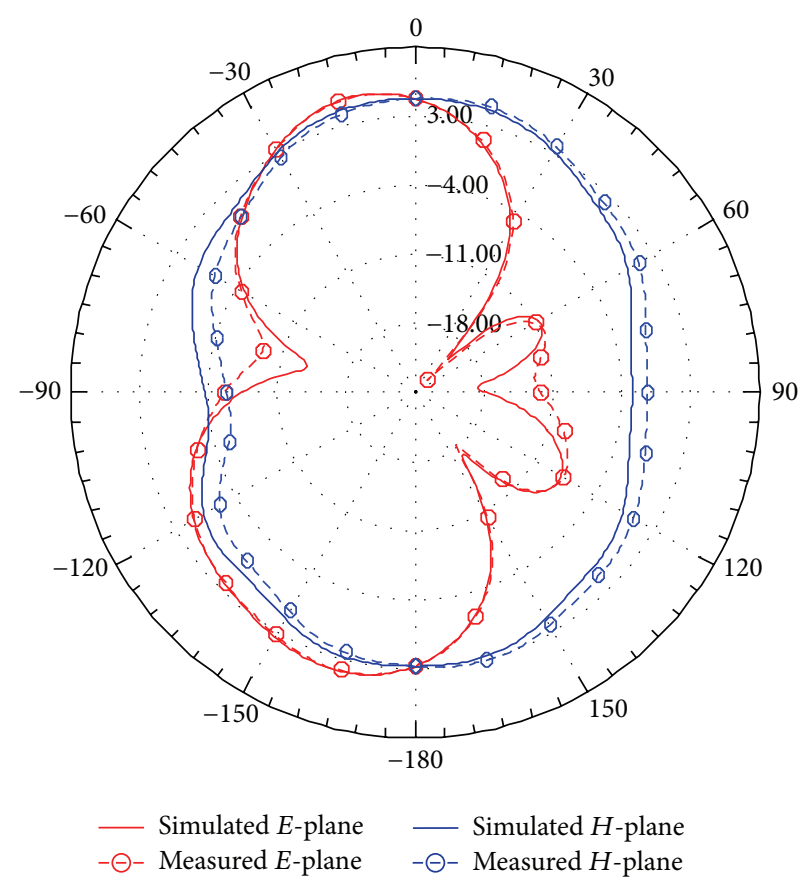

(d)

FIGURE 10: Simulated and measured radiation patterns at (a) $2.5 \mathrm{GHz}$, (b) $3.5 \mathrm{GHz}$, (c) $5.5 \mathrm{GHz}$, and (d) $8 \mathrm{GHz}$ resonance frequencies. 
Guangdong Province under Grant no. 2013B090500007, in part by the Dongguan Project on the Integration of Industry, Education, and Research under Grant no. 2014509102205, and in part by the Fundamental Research Funds for the Central Universities of Central South University under Grant no. $2016 z z t s 340$.

\section{References}

[1] J. F. V. Valdes, S. Burgos, A. M. Acevedo, and P. Padilla, "Antenna measurement systems and antenna technology for next wireless generation," International Journal of Antennas and Propagation, vol. 2013, Article ID 527582, 2 pages, 2013.

[2] K.-L. Wong and L.-C. Lee, "Multiband printed monopole slot antenna for WWAN operation in the laptop computer," IEEE Transactions on Antennas and Propagation, vol. 57, no. 2, pp. 324-330, 2009.

[3] X. L. Sun, S. W. Cheung, and T. I. Yuk, "Dual-band monopole antenna with compact radiator for $2.4 / 3.5 \mathrm{GHz}$ WiMAX applications," Microwave and Optical Technology Letters, vol. 55, no. 8, pp. 1765-1770, 2013.

[4] J. Malik, A. Patnaik, and M. V. Kartikeyan, "A compact dualband antenna with omnidirectional radiation pattern," IEEE Antennas and Wireless Propagation Letters, vol. 14, pp. 503-506, 2015.

[5] P. Liu, Y. Zou, B. Xie, X. Liu, and B. Sun, "Compact CPWfed tri-band printed antenna with meandering split-ring slot for WLAN/WiMAX applications," IEEE Antennas and Wireless Propagation Letters, vol. 11, pp. 1242-1244, 2012.

[6] J. Pei, A.-G. Wang, S. Gao, and W. Leng, "Miniaturized triple-band antenna with a defected ground plane for WLAN/WiMAX applications," IEEE Antennas and Wireless Propagation Letters, vol. 10, pp. 298-301, 2011.

[7] Y. Jee and Y.-M. Seo, "Triple-band CPW-fed compact monopole antennas for GSM/PCS/DCS/WCDMA applications," Electronics Letters, vol. 45, no. 9, pp. 446-448, 2009.

[8] T.-H. Chang and J.-F. Kiang, "Compact multi-band H-shaped slot antenna," IEEE Transactions on Antennas and Propagation, vol. 61, no. 8, pp. 4345-4349, 2013.

[9] M. Kim, W. Lee, and Y. J. Yoon, "A multi-band internal antenna for all commercial mobile communication bands and $802.11 \mathrm{a} / \mathrm{b} / \mathrm{g} / \mathrm{n}$ WLAN," in Proceedings of the Asia-Pacific Microwave Conference (APMC '11), pp. 171-174, Melbourne, Australia, December 2011.

[10] P. Beigi, J. Nourinia, Y. Zehforoosh, and B. Mohammadi, "A compact novel CPW-FED antenna with square spiral-patch for multiband applications," Microwave and Optical Technology Letters, vol. 57, no. 1, pp. 111-115, 2015.

[11] W. Hu, Y.-Z. Yin, P. Fei, and X. Yang, "Compact triband squareslot antenna with symmetrical L-strips for WLAN/WiMAX applications," IEEE Antennas and Wireless Propagation Letters, vol. 10, pp. 462-465, 2011.

[12] D.-H. Hsieh, J.-W. Wu, Y.-W. Cheng, and C.-J. Wang, "A CPWfed meandered-shaped monopole antenna with asymmetrical ground planes," in Proceedings of the IEEE Radio and Wireless Symposium (RWS '15), pp. 86-88, IEEE, San Diego, Calif, USA, January 2015.

[13] Y. F. Cao, S. W. Cheung, and T. I. Yuk, "A multiband slot antenna for GPS/WiMAX/WLAN systems," IEEE Transactions on Antennas and Propagation, vol. 63, no. 3, pp. 952-958, 2015.
[14] B. Yildirim, E. Basaran, and B. Turetken, "Dielectric-loaded compact WLAN/WCDMA antenna with shorted loop and monopole elements," IEEE Antennas and Wireless Propagation Letters, vol. 12, pp. 288-291, 2013. 


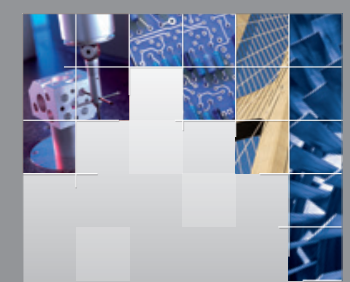

\section{Enfincering}
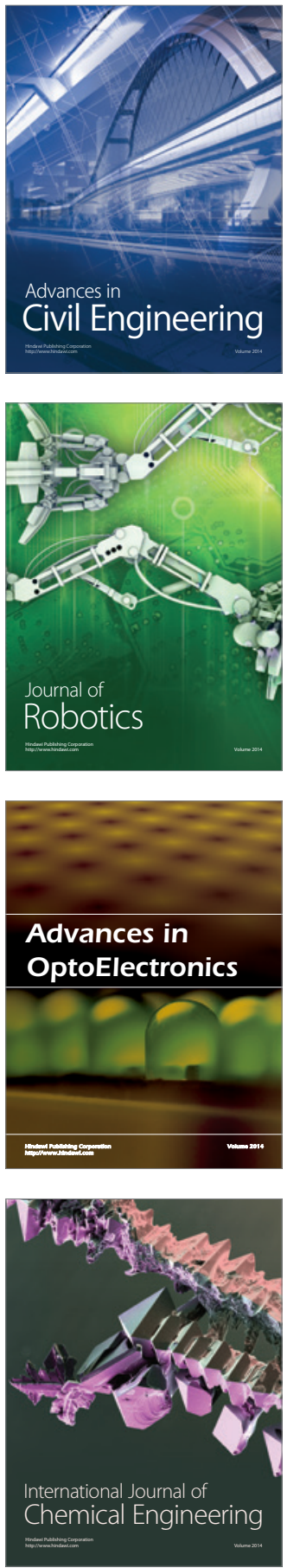

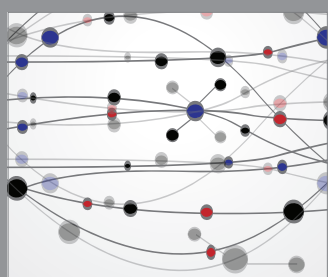

The Scientific World Journal

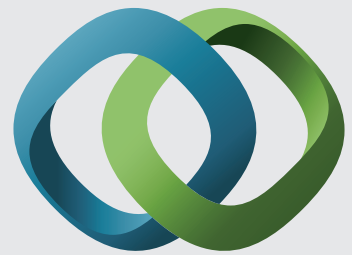

\section{Hindawi}

Submit your manuscripts at

http://www.hindawi.com
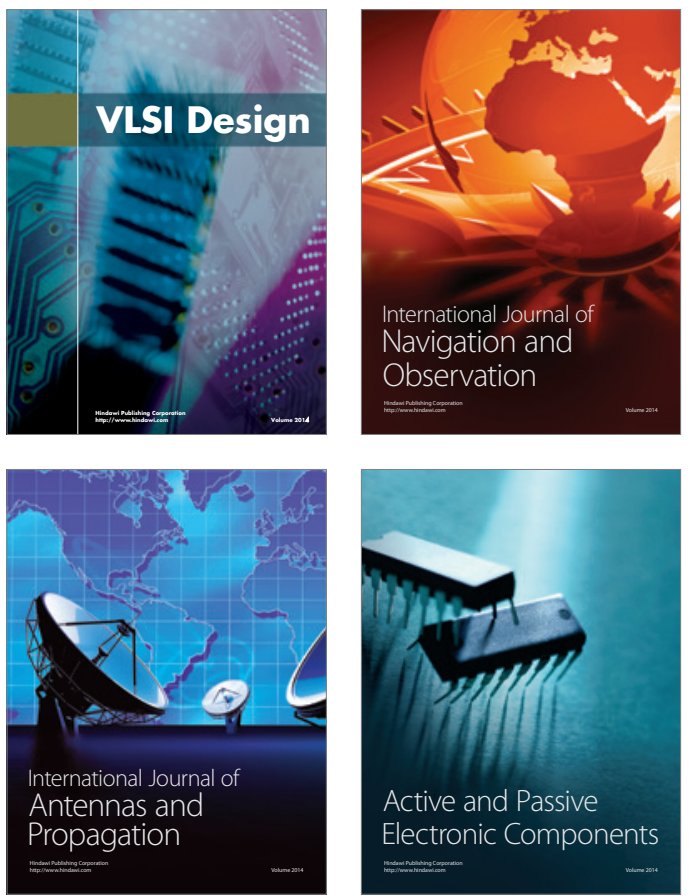
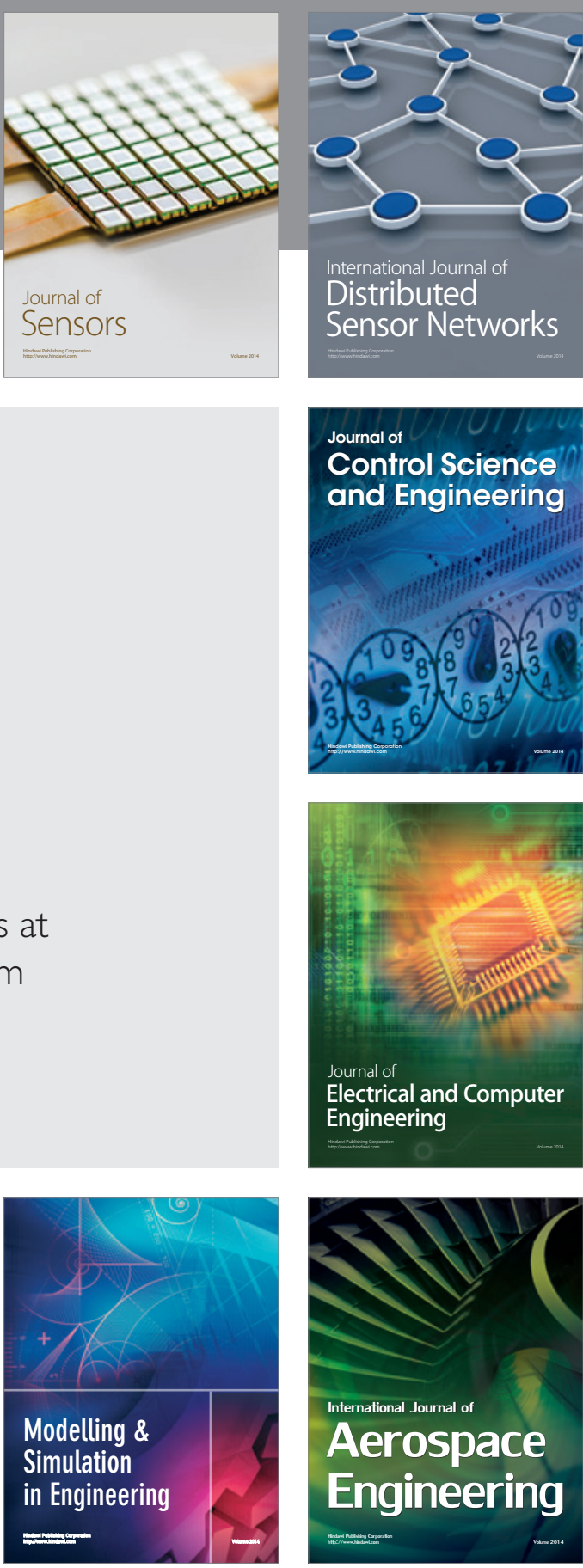

International Journal of

Distributed

Sensor Networks

Journal of

Control Science

and Engineering
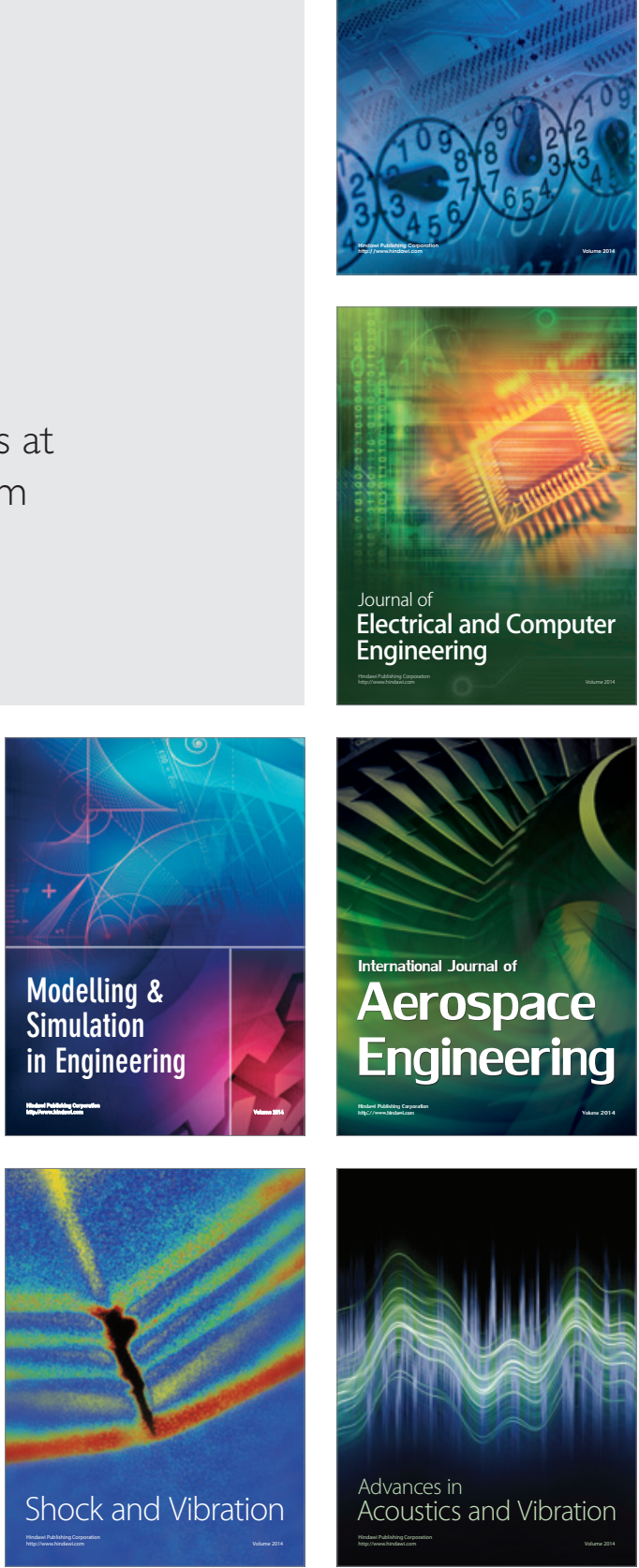